\title{
Importância do dismorfismo eritrocitário na investigação da origem da hematúria: revisão da literatura
}

Primeira submissão em 10/09/03 Última submissão em 27/07/04 Aceito para publicação em 01/02/05 Publicado em 20/04/05

\section{The importance of the dysmorphic erythrocyte for investigation of the source of hematuria: literature review}

Leonardo de Souza Vasconcellos'; Maria Goretti Moreira Guimarães Penido²; Pedro Guatimosim Vidigal

\begin{abstract}
unitermos Dismorfismo eritrocitário resumo

Morfologia das hemácias

Hematúria glomerular

Sangramento glomerular

Urinálise

Artigo de revisão

As hematúrias são achados comuns nos exames de urina de rotina e nem sempre são sinais de doenças. A presença de hematúria associada a outras alterações urinárias, especialmente a proteinúria, sugere comprometimento do trato urinário e merece investigação. Na literatura são inúmeros os trabalhos que valorizam a sedimentoscopia urinária, principalmente a morfologia das hemácias, como indicativo do local do sangramento: se glomerular ou não-glomerular. Neste artigo, os autores revisam o estudo do dismorfismo eritrocitário, enfatizando a definição, a fisiopatologia, os métodos, os valores de referência e as limitações apontadas na literatura. As comparações com demais marcadores de hemorragia glomerular também foram discutidas. No final, os autores relatam como a literatura interpreta e utiliza os resultados da pesquisa do dismorfismo eritrocitário para guiar a propedêutica complementar na investigação da origem da hematúria.
\end{abstract}

The hematurias are a frequent finding in urinary routine exams and do not necessarily indicate illness. The presence of hematuria associated with other urinary disturbances, especially proteinuria, indicates urinary tract pathology and should be investigated. In the literature, several studies point out the importance of urinary sedimentoscopy, specially the red cells morphology, to determine the source of bleeding: glomerular or non-glomerular. In this article, the authors review the dysmorphic erythrocyte, emphasizing on the meaning, the physiopathology, the methods, the cut-of values, and the limitations according to the literature. The comparisons with other markers of glomerular bleeding were also discussed. At the end, the authors exposed how the literature analyses and applies the dysmorphic erythrocyte results to guide the complementary research for investigation the source of urinary bleeding. key words

Dysmorphic erythrocyte

Red cells morphology

Glomerular hematuria

Glomerular bleeding

Urinalysis

Review article

\section{Introdução}

Hematúria é definida na literatura como a eliminação de um número anormal de hemácias na urina e, devido à sua complexidade, apresenta diversas propostas de classificação ${ }^{(30)}$. Quanto à sua localização, as hematúrias podem ser classificadas em glomerulares, de origem nefrológica, ou não-glomerulares, de origem urológica. Quanto à intensidade do sangramento, são identificadas como macroscópicas, quando a coloração da urina sugere a presença de sangue, ou microscópicas, quando as hemácias são detectadas somente pela sedimentoscopia urinária. Quanto à freqüência, podem se apresentar de forma permanente (presença constante de hemácias no

1. Mestrando em Medicina; residente de Patologia Clínica/Medicina Laboratorial do Hospital das Clínicas da Universidade Federal de Minas Cerais (HC/EFMC).

2. Doutora em Medicina; professora-adjunta do Departamento de Pediatria da Faculdade de Medicina da UFMG.

3. Doutor em Medicina; professor-adjunto do Departamento de Propedêutica Complementar da Faculdade de Medicina da UFMG. 
sedimento urinário), isolada (episódio único de hematúria), ou recorrente, quando há períodos de remissão do episódio hematúrico, com intervalos variáveis de meses até anos. Finalmente, quanto à repercussão clínica, são referidas ainda como sintomáticas ou assintomáticas ${ }^{(4)}$.

As hematúrias isoladas e assintomáticas merecem especial atenção pela freqüência cada vez maior entre os diagnósticos clínicos, causando grande ansiedade no paciente e em seus familiares. Na prática diária, elas aparecem como a segunda causa de consultas nefrológicas entre crianças e adolescentes. Vehaskari et al. ${ }^{(65)}$ (1979) encontraram prevalência entre $0,5 \%$ e $4 \%$ em crianças. Nos adultos, foi de $20 \%$, segundo estudos de Messing et al. ${ }^{(40)}$ (1995). Outros autores encontraram prevalência de hematúria microscópica assintomática, na população geral, entre 0,5\% e 22\%, dependendo da idade da população estudada e do número de hemácias considerado normal ${ }^{(4)}$.

O achado de hemácias na urina ocorre freqüentemente de maneira ocasional, principalmente quando se utiliza o exame físico-químico por fitas reagentes para detecção de hemácias (hemoglobina) em exames de rotina ${ }^{(4,5)}$. No entanto, isso não traduz necessariamente um estado de doença. Algumas vezes, pode anunciar enfermidades nefrológicas ou urológicas e, nesses casos, são constantes as discussões na literatura sobre a validade de sua investigação, bem como a adoção de uma propedêutica mais adequada para a localização desses sangramentos ${ }^{(44)}$. As principais causas de hematúria glomerular e não-glomerular estão listadas na Tabela 1.

A investigação de hematúria requer anamnese e exame físico detalhados, bem como utilização de exames complementares adequados, sejam laboratoriais ou de imagem, evitando procedimentos agressivos, onerosos e muitas vezes desnecessários. A hemorragia glomerular é classicamente caracterizada pela presença de proteinúria e cilindros hemáticos. Entretanto, nem todos os pacientes portadores de glomerulonefrite apresentam tais alterações ${ }^{(4,30,44)}$. Atualmente, têm-se valorizado outros achados na sedimentoscopia urinária, principalmente aqueles baseados na morfologia das hemácias, indicando com maior precisão o local do sangramento: se glomerular ou não-glomerular $(6,7,12,13,17,27,41)$.

Nessa revisão, os autores avaliam a validade do estudo do dismorfismo eritrocitário pela análise da sedimentoscopia urinária, enfatizando principalmente a definição, a fisiopatologia, os métodos e os valores de referência adotados na literatura. As limitações de seu uso e comparações com demais marcadores de hemorragia glomerular também foram

\section{Tabela 1 Principais causas de hematúrias glomerulares e não-glomerulares}

\begin{tabular}{lll}
\hline Hematúrias glomerulares & Hematúrias não-glomerulares \\
Proliferativa & Crescêntica & Causas hematológicas/defeito plaquetário \\
& Lúpica & Corpo estranho/cateteres \\
& Membranoproliferativa & Fístula arteriovenosa/trombose veia renal \\
& Nefropatia IgA (doença de Berger) & Hemangioma vesical/renal \\
& Proliferativa mesangial & Hematúria de exercício \\
& Púrpura de Henoch-Schönlein & Hipertrofia prostática \\
& & Infecções/tuberculose \\
Não-proliferativa & Malformações renais (cistos) \\
& Nefrite hereditária progressiva & Metabólicas/hipercalciúria e hiperuricosúria \\
& Nefropatia membranosa & Medicamentosa/anticoagulantes \\
& Nefroesclerose & Nefrolitíase \\
Membrana basal & Síndrome de Alport & Obstrução do trato urinário \\
& & Queimaduras \\
& & Tabagismo \\
& Trauma abdominal/cirurgias
\end{tabular}


foco desse manuscrito. Por fim, os autores apontam o uso de outros exames complementares adotados na literatura para a investigação de hematúria.

\section{Definição}

No final da década de 1970, Birch e Fairley ${ }^{(7)}$ (1979), analisando o sedimento urinário em microscopia de contraste de fase, demonstraram uma possibilidade de distinção entre hematúrias glomerulares e não-glomerulares, baseando-se não apenas no encontro de proteinúria e cilindrúria, mas também na diferenciação morfológica das diversas populações de hemácia na urina. Segundo esses autores, a hematúria não-glomerular caracterizar-se-ia por hemácias urinárias isomórficas, com tamanho uniforme e morfologia semelhante às encontradas na circulação sangüínea (Figura 1). Por outro lado, na hematúria glomerular, as hemácias se apresentariam dismórficas, com alterações em forma, cor, volume e conteúdo de hemoglobina, podendo-se encontrar diversas projeções em suas membranas celulares, bem como heterogeneidade citoplasmática e forma bicôncava ou esférica (Figura 2).

Esses achados originais, realizados em microscopia de contraste de fase, foram repetidos e confirmados por outros autores, como Fasset et al. ${ }^{(17)}$ (1982), De Santo et al. ${ }^{(13)}$ (1987), Mohammad et al. ${ }^{(41)}$ (1993), Crompton et al. ${ }^{(12)}$ (1993), Ahmad G et al.(2) (1993) e Van der Snoek et al.(63) (1994). Ainda na década de 1980, outros pesquisadores, como Stapleton et al. ${ }^{(58)}$ (1983) e Rath et al. ${ }^{(50)}$ (1990), propuseram o uso da microscopia ótica para a pesquisa de dismorfismo eritrocitário em sedimentos urinários corados. Chang ${ }^{(10)}$ (1984), avaliando a sedimentoscopia

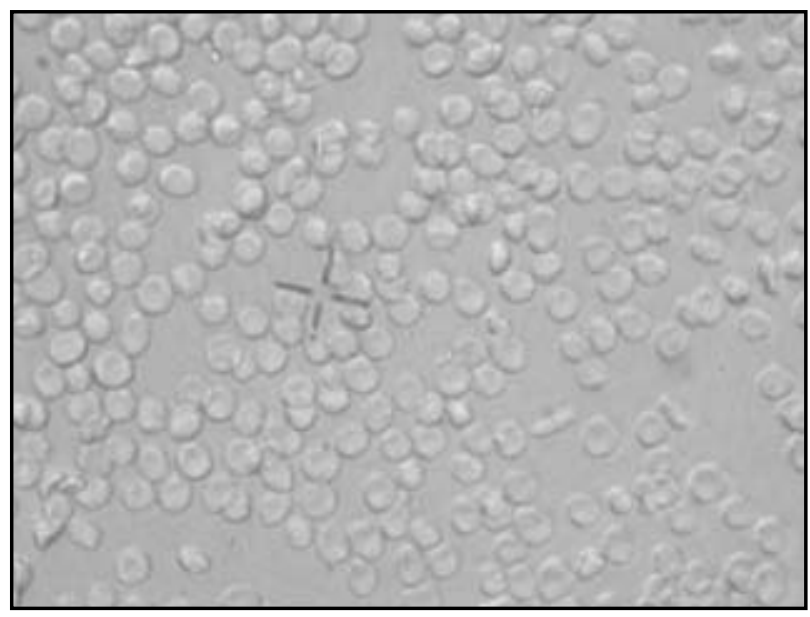

Figura 1 - Sedimentoscopia urinária de hematúria não-glomerular, com presença de inúmeras hemácias isomórficas. Microscopia de contraste de fase (100x) urinária corada pelo corante de Wright em 20 pacientes com hematúria e utilizando como critério de dismorfismo a presença de anisocitose e hipocromia, obteve $100 \%$ de concordância com os achados de biópsia renal nos diagnósticos da origem da hematúria: se glomerular ou não-glomerular. O estudo do dismorfismo eritrocitário também pode ser evidenciado pela microscopia eletrônica, conforme trabalhos de Fassett et al. ${ }^{(18)}$ (1982) e Brich et al. ${ }^{(6)}$ (1983), bem como por analisadores de imagens computadorizadas, segundo dados de Di Paolo et al.(14) (1993), ressaltando sua importância na detecção de hematúria glomerular.

No início da década de 1990, duas linhas de pesquisas distintas estudaram o dismorfismo eritrocitário pela análise de um único tipo celular. Entre as diversas formas de hemácias observadas na urina, como anulócitos, codócitos, equinócitos, esquizócitos, estomatócitos e nizócitos, foram os acantócitos e as células glomerular shapes (G1) considerados os mais específicos para lesões glomerulares ${ }^{(25,}$ 35, 42, 61). Inicialmente descritos por Kohler et al. ${ }^{(35)}$ (1991), os acantócitos são hemácias que possuem forma de anel e apresentam protrusões citoplasmáticas vesiculares. Já as células G1, inicialmente descritas por Tomita et al. ${ }^{(61)}$ (1992), caracterizadas por sua forma de rosca e podendo apresentar uma ou mais projeções vesiculares em sua superfície, foram as que apresentaram maiores sensibilidade e especificidade, entre um grupo de cinco tipos de hemácias glomerulares (G1 a G5) inicialmente propostos por esses autores, para diagnóstico de sangramento glomerular.

A Tabela 2 descreve os tipos mais comuns de populações de hemácias que podem ser encontrados em sedimentoscopia urinária( ${ }^{(4)}$.

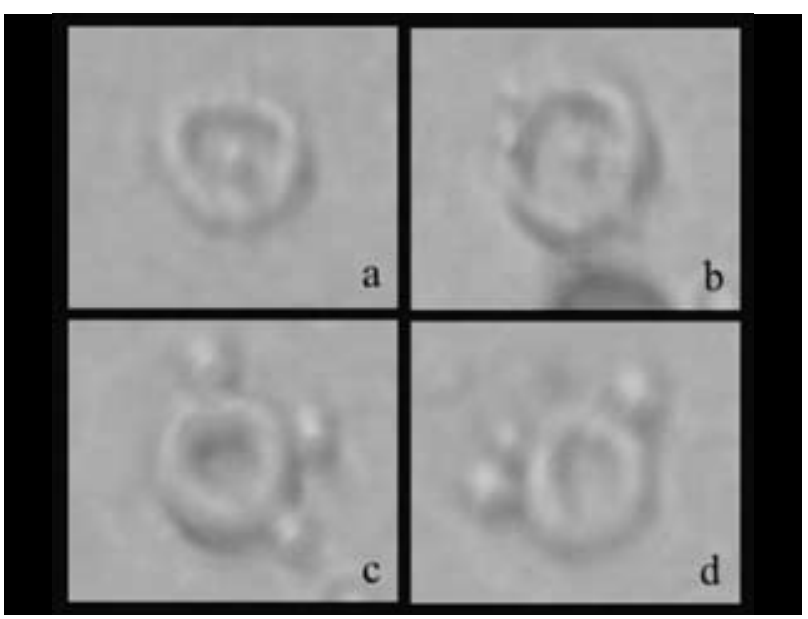

Figura 2 - Hemácias dismórficas presentes em hemorragias glomerulares. Codócitos $(a, b)$ e acantócitos (c, d). Microscopia de contraste de fase (100x) 


\section{Tabela 2 Populações de hemácias encontradas em sedimentoscopia urinária}

População
Acantócito
Anulócito
Células G1
Codócito
Discócito
Equinócito
Esquizócito
Estomatócito
Hemácias fantasmas
Nizócito

\section{Fisiopatologia}

Muitos estudos tentaram explicar o mecanismo de surgimento de eritrócitos na urina, com destaque para a lesão glomerular e as alterações na permeabilidade dos túbulos, ductos e trato urinário restante ${ }^{(4,30,44)}$. Geralmente, quando não-glomerulares, também chamadas de pós-glomerulares ou extraglomerulares, as hemácias são provenientes dos túbulos, ductos ou de todo o trato urinário restante, apresentando-se na forma isomórfica. Quando se originam nos glomérulos, também chamadas de hemorragias glomerulares, as hemácias variam em forma, dimensão e conteúdo de hemoglobina, apresentando-se dismórficas $(6,12-14,17,18,35,41,50)$.

Entretanto, há mais de duas décadas a literatura vem procurando explicações para as alterações dismórficas dos eritrócitos de origem glomerular. Inicialmente, procuraramse explicações com base na lesão osmótica e química dos eritrócitos $(29,34,36,51,52)$. Essa teoria fundamentava-se em danos na membrana celular das hemácias e na perda de hemoglobina ao tramitarem pelos diversos segmentos do néfron, juntamente com constantes mudanças de soluções de diversas concentrações iônicas e osmolaridades ${ }^{(29,51)}$. Muitos trabalhos visaram a reproduzir essas lesões in vitro e alguns obtiveram sucesso, como Jones ${ }^{(29)}$ (1991) e Rath et al.(51) (1992), que relataram hemólise parcial em meio hipotônico, e Kitamoto et al.(34) (1992), que verificaram deformações das hemácias após variações de pH. Porém, outros autores, como Rizzoni et al. ${ }^{(52)}$ (1983), não conseguiram alterar a morfologia eritrocitária após variações do $\mathrm{pH} \mathrm{e}$ da densidade urinária. Kubota et al. ${ }^{(36)}$ (1988) também não encontraram diferenças de $\mathrm{pH}$ urinário comparando grupos com e sem dismorfismo eritrocitário. Devido ao insucesso desses estudos, novas explicações seriam necessárias para os achados de dismorfismo.

Posteriormente, sugeriu-se ser o traumatismo mecânico o possivel causador do dismorfismo ${ }^{(36,44,53)}$. Ao atravessarem a membrana basal glomerular pelos hiatos existentes entre seus capilares, os eritrócitos urinários sofreriam uma compressão importante, com conseqüentes deformação de sua membrana celular e redução de volume. Essas alterações foram reproduzidas por Kubota et al. ${ }^{(36)}$ (1988), fazendo ensaios em que hemácias atravessavam poros de $3 \mu \mathrm{m}$ sob pressão.

A liberação de mediadores químicos e de enzimas digestivas, após lesão celular, na vigência de quadros infecciosos ou de processos inflamatórios glomerulares $(35,46,53)$, e as eritrofagocitoses ${ }^{(31)}$, pelas células tubulares renais, também foram apontadas como possíveis fatores de deformidade das hemácias. Embora a teoria mecânica venha sendo mais aceita atualmente na literatura, seria mais prudente acreditar na miscelânea de todos os fatores acima como determinantes das alterações do dismorfismo eritrocitário(31, 36, 46, 53).

\section{Fatores pré-analíticos e coleta urinária}

Devido à importância de se realizar uma coleta adequada para garantir a representatividade da amostra, vários estudos na literatura relacionaram alguns fatores pré-analíticos capazes de interferir na avaliação do dismorfismo eritrocitário(16,32, 41, 54,57,59).

Após assepsia da região genital, coletar preferencialmente o jato médio da primeira urina da manhã, ou de 
qualquer outra hora, desde que se respeite estase vesical de pelo menos 2 a 4 horas $(7,8,13,17)$. Alguns autores relatam uma preferência pela primeira urina da manhã, que, por ser mais ácida e mais concentrada, preservaria os cilindros, os elementos celulares e todos os demais componentes do

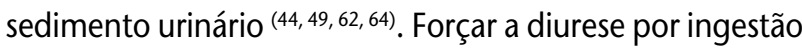
de grande quantidade de líquido não é aconselhado, segundo trabalho de Schuetz et al.(54) (1985), pois as hemácias seriam facilmente lisadas em urinas diluídas (densidade < 1.006). Embora não seja critério de exclusão, a prática de exercícios físicos intensos prévios à coleta também seria desaconselhada por alguns autores, pois a relação entre exercício físico e hematúria, descrita por Collier desde 1907 (citado por Kesson et al. $\left.{ }^{(30)}\right)$, é confirmada por vários estudos na literatura ${ }^{(4,18,32,44)}$. Em casos de períodos menstruais ou trauma do trato urinário, sugere-se aguardar alguns dias para a realização do exame ${ }^{(4,62)}$.

Ainda se discute se o tempo entre a coleta da amostra e a realização do ensaio laboratorial seria capaz de alterar a morfologia das hemácias. Stapleton et al. ${ }^{(58)}$ (1987) aconselharam a realização do teste no máximo até 60 minutos após a coleta. Por outro lado, existem trabalhos, como o de Rizzoni et al. ${ }^{(52)}$ (1983), que não encontraram mudanças nos padrões dismórficos dos eritrócitos relacionadas com o horário da coleta e o tempo entre esta e a análise. Mohammad et al.(41) (1993), avaliando lâminas a fresco após 16 horas e lâminas fixadas após 12 dias, observaram que a proporção de células dismórficas se manteve inalterada. Embora controverso, recomenda-se um tempo máximo de 2 a 4 horas entre a coleta e o exame urinário, para não ocorrer interferência por alcalinização, proliferação bacteriana ou outros fatores que possam alterar a morfologia das hemácias ${ }^{(44)}$.

\section{Método laboratorial}

A microscopia por contraste de fase parece ser o melhor método de análise do sedimento urinário, principalmente para o estudo do dismorfismo eritrocitário, dispensando o uso de colorações especiais $(7,8,34-37,41,52,61,62,64,67)$. As etapas de sua realização mostram-se semelhantes entre as várias metodologias empregadas em trabalhos da literatura ${ }^{(34,37,}$ 67). Após a coleta, centrifugam-se $10 \mathrm{ml}$ de urina durante 5-10 minutos, numa velocidade de $400 \mathrm{~g}$ ou a $1.500 \mathrm{rpm}$. Posteriormente, removem-se $9,5 \mathrm{ml}$ do líquido sobrenadante e gentilmente ressuspende-se o sedimento naquele $0,5 \mathrm{ml}$ de urina restante, de onde se retira pequena alíquota para exame microscópico. Nessa alíquota identificam-se as populações celulares, sendo necessário análise de pelo menos cem eritrócitos para avaliação do dismorfismo (11, $39,47,48,66)$

\section{Valores de referência}

Os valores laboratoriais utilizados para a definição de hematúria ainda são controversos. Alguns autores consideram hematúria a presença de cinco ou mais hemácias por campo microscópico de grande aumento (400x), após centrifugação da amostra urinária, em pelo menos dois exames de urina distintos ${ }^{(4,4)}$. Outros consideram hematúria um número superior a dez hemácias por campo $400 x^{(5,45)}$. Existem trabalhos que preferem avaliar a presença de hemácias por mililitro ( $\mathrm{ml}$ ) de urina após centrifugação, considerando hematúria valores acima de 8 mil hemácias $/ \mathrm{ml}$ de urina e hematúria macroscópica $>10^{6}$ hemácias $/ \mathrm{ml}$ de urina ${ }^{(4,44)}$. Habitualmente, o valor de 5 mil hemácias/ml de urina vem sendo adotado como limite superior da normalidade por muitos laboratórios.

Na definição de dismorfismo eritrocitário, Birch e Fairley ${ }^{(7)}$ (1979) consideraram o limite para caracterização de hemorragia glomerular a presença de quatro ou mais diferentes populações de hemácias. Mesmo não definindo um valor percentual de dismorfismo limítrofe de normalidade, esses autores já haviam observado que, quanto maior fosse esse percentual, maior seria a probabilidade de lesão glomerular. Vários trabalhos procuraram determinar esse valor de referência: alguns autores adotam a presença de, no mínimo, 20\% de dismorfismo como indicativo de hematúria glomerular, tanto para crianças quanto para adultos ${ }^{15,38,}$ 41, 58). Outros encontraram bons resultados utilizando um limite de $10 \%{ }^{(67)}$. Entretanto, outros artigos, como o de De Santo et al. ${ }^{(13)}$ (1987), visando a aumentar a sensibilidade do teste, propõem elevação do valor de corte para $80 \%$, o mesmo recomendado pela Associação Americana de Urologia(24). Diante do exposto, fica claro que ainda não existe um consenso na literatura sobre qual porcentagem de dismorfismo eritrocitário deve ser adotada (e se deve ser adotado algum percentual) para definir hematúria glomerular. Isso porque, dependendo da metodologia empregada e do tipo de morfologia considerada dismórfica, não se pode afirmar que a adoção de um determinado percentual oferece melhores resultados ${ }^{(22)}$.

Quanto ao valor limítrofe para o encontro de acantócitos, Kohler et al.(35) (1991) relataram especificidade de $98 \%$ e sensibilidade de $52 \%$ para hematúria glomerular, considerando uma presença de pelo menos $>5 \%$ na urina. 
Recentemente, Catala et al.(9) (2002), adotando esse mesmo limite, também evidenciaram bom resultados, com sensibilidade de $88 \%$ e especificidade de $100 \%$. Para as células G1, os estudos iniciais de Tomita et al. ${ }^{(61)}$ (1992) obtiveram sensibilidade de $89 \%$ e especificidade de $95 \%$ para lesão glomerular, considerando o limite de $>1 \%$. Kitamoto et al. ${ }^{(33)}$ (1993) e Lettgen e Wohlmuth ${ }^{(37)}$ (1995), propondo limite $>5 \%$, obtiveram $100 \%$ de especificidade.

Embora exista uma variação de $1 \%$ a $35 \%$ para o limite de normalidade $(4,15,25,33,37,38,42,44,61,68)$, a maioria dos autores prefere adotar o valor de $\geq 5 \%$ de acantócitos ou de células $\mathrm{G} 1$ como referência para caracterização da hematúria de origem glomerular, obtendo melhores resultados em relação ao percentual de $80 \%$ de dismorfismo adotado por estudos simpatizantes ao de Birch e

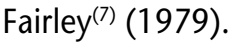

A Tabela 3 lista vários estudos na literatura que avaliaram a sensibilidade e a especificidade após adoção de diversos valores de referência para o dismorfismo eritrocitário como marcador urinário de hematúria glomerular.

Relação de alguns trabalhos na literatura com seus critérios de dismorfismo eritrocitário e os Tabela 3 valores de sensibilidade e especificidade obtidos para hematúria glomerular

\begin{tabular}{|c|c|c|c|}
\hline Autores (ano) & Critérios de dismorfismo & Sensibilidade (\%) & Especificidade (\%) \\
\hline Birch e Fairley $(1979)^{(7)}$ & > 4 populações diferentes de hemácias & 99 & 93 \\
\hline Birch et al. $(1983)^{(6)}$ & > 4 populações diferentes de hemácias & 95 & 100 \\
\hline Abdurrahman et al. (1985) ${ }^{(1)}$ & $>15 \%$ dismorfismo & 93 & 100 \\
\hline Pillsworth et al. $(1987)^{(47)}$ & $>14 \%$ dismorfismo & 94 & 100 \\
\hline De Santo et al. $(1987)^{(13)}$ & $>80 \%$ dismorfismo & 96 & 93 \\
\hline Stapleton $(1987)^{(58)}$ & $>20 \%$ dismorfismo & 92 & 94 \\
\hline Kohler et al. (1991) $)^{(35)}$ & $>5 \%$ acantócitos & 52 & 98 \\
\hline Tomita et al. (1992) $)^{(61)}$ & > 1\% células $\mathrm{G} 1$ & 89 & 95 \\
\hline Ahmad G. et al. $(1993)^{(2)}$ & $>20 \%$ dismorfismo & 93,6 & 97,7 \\
\hline \multirow[t]{2}{*}{ Kitamoto et al. (1993) $)^{(33)}$} & > 5\% células G1 & 73 & 100 \\
\hline & $>5 \%$ de células $\mathrm{G} 1$ (urina $\mathrm{pH}<6,4$ ) & 99,2 & 100 \\
\hline Mohammad et al. $(1993)^{(41)}$ & $>20 \%$ dismorfismo & 90 & 100 \\
\hline Crompton et al. $(1993)^{(12)}$ & $>40 \%$ dismorfismo & $93-95$ & $95-100$ \\
\hline van der Snoek et al. $(1994)^{(63)}$ & $>40 \%$ dismorfismo & 100 & 66,7 \\
\hline \multirow[t]{2}{*}{ Ling S. H. et al. $(1994)^{(38)}$} & > 1\% células $\mathrm{G} 1$ & 75,7 & 96,5 \\
\hline & $>20 \%$ células $\mathrm{G} 1$ & 95,9 & 95,9 \\
\hline \multirow[t]{2}{*}{ Lettgen e Wohlmuth (1995) ${ }^{(37)}$} & $>30 \%$ dismorfismo & 71 & 100 \\
\hline & > 5\% células G1 & 100 & 100 \\
\hline \multirow[t]{2}{*}{ Dinda et al. $(1997)^{(15)}$} & $>20 \%$ dismorfismo & 82 & 100 \\
\hline & $>5 \% \mathrm{G} 1$ & 100 & 100 \\
\hline \multirow[t]{4}{*}{ Zaman e Proesman $(2000)^{(67)}$} & $>50 \%$ dismorfismo ou $>1 \%$ G1 & 93 & 44 \\
\hline & $>50 \%$ dismorfismo e $>1 \%$ G1 & 60 & 91 \\
\hline & $>10,20,50$ e $90 \%$ dismorfismo & $95,95,93,62$ & $24,34,43,85$ \\
\hline & $>1,2,5,10 \% \mathrm{G} 1$ & $62,40,28,10$ & $89,95,95,98$ \\
\hline \multirow[t]{2}{*}{ Catala et al. $(2002)^{(9)}$} & $>35 \%$ dismorfismo & 69 & 100 \\
\hline & $>5 \%$ acantócitos & 88 & 100 \\
\hline
\end{tabular}




\section{Comparação com demais marcadores de hematúria}

Além da adoção do dismorfismo eritrocitário para investigação de sangramento glomerular, existem outros marcadores laboratoriais para diferenciação entre as hematúrias glomerulares e não-glomerulares, muitos bastante utilizados na prática literária ${ }^{(4,19,20,23,26,28,30,44,56)}$. A Tabela 4 lista esses principais marcadores, indicando seus valores de corte para diferenciação entre hematúria glomerular e não-glomerular. A seguir, destacamos as características de alguns desses marcadores, confrontando-as com o método do dismorfismo eritrocitário.

\section{Cilindros hemáticos}

Os cilindros hemáticos são estruturas formadas no interior dos túbulos renais pelo aprisionamento de hemácias pela mucoproteína de Tamm-Horsfall em precipitação ${ }^{(5,}$ ${ }^{44,62}$. A sua presença é altamente sugestiva de hematúria glomerular, muito embora a sua ausência não exclua o diagnóstico de glomerulonefrite. Alguns trabalhos, como o de Raman et al.(49) (1986), apontam os cilindros hemáticos mais eficazes em comparação com a pesquisa do dismorfismo eritrocitário como marcadores de lesão glomerular. Entretanto, esses dados são ainda conflitantes na literatura. Mohammad et al. ${ }^{(41)}$ (1993) questionam a metodologia adotada por Raman et al.(49) (1986), pois, ao avaliarem a presença de dismorfismo utilizando campo microscópio de menor aumento (100x), e não o de grande aumento (400x), a sensibilidade e a especificidade dos resultados estariam comprometidas. Muitos trabalhos apontam vantagens do estudo do dismorfismo em relação aos cilindros hemáticos, uma vez que, diferentemente das hemácias isoladas, que não se alteram quando a urina está na faixa fisiológica de $\mathrm{pH}$, osmolaridade e concentração ácida, os cilindros hemáticos são estruturas mais frágeis e de fácil desintegração, principalmente em urinas alcalinas, na presença de bactérias desdobradoras de uréia, bem como no processo de centrifugação urinária ${ }^{(4)}$. Embora seja raro, Singala et al. ${ }^{(56)}$ (1978) demonstraram que é possível encontrar cilindros hemáticos em pacientes com nefrite túbulo-intersticial aguda, mesmo na ausência de lesão glomerular. Do mesmo modo, Kohler et al. ${ }^{(35)}$ (1991) verificaram que nem todas as glomerulonefrites se expressavam com cilindrúria.

\section{Proteinúria}

Pequena quantidade de proteína pode ser encontrada na urina, conhecida como proteinúria fisiológica, com valores de até $<0,15 \mathrm{~g} / 24 \mathrm{~h}$ (ou $<4 \mathrm{mg} / \mathrm{m}^{2} /$ hora $)^{(4,19,20)}$. Caso ocorra elevação desses valores, a proteinúria passa a ser patológica e merece investigação. A proteinúria pode ser estratificada em três estádios: leve $(0,15$ a $1 \mathrm{~g} / 24 \mathrm{~h})$, moderada ( 1 a $3 \mathrm{~g} / 24 \mathrm{~h}$ ) e maciça (se $>3 \mathrm{~g} / 24 \mathrm{~h}$ ou se $>$ $\left.40 \mathrm{mg} / \mathrm{m}^{2} / \mathrm{hora}\right)$; ou, ainda, se em urina de amostra única

\section{Tabela 4 Marcadores urinários das hematúrias glomerulares e não-glomerulares}

\section{Marcadores urinários}

Acantócitos

Células G1

Cilindros hemáticos

Dismorfismo eritrocitário

Microalbuminúria

Número de população de hemácias diferentes

Proteinúria

Razão entre volume celular médio das hemácias na urina e volume corpuscular médio sangüíneo: $\mathrm{VCM}_{\mathrm{u}} / \mathrm{VCM}_{\mathrm{s}}$ Teste das hemácias envolvidas por proteína Tamm-Horsfall
Hematúrias não-glomerulares

$$
\begin{array}{ll}
<5 \% & \geq 5 \% \\
<5 \% & \geq 5 \%
\end{array}
$$

Ausentes

Ausente

$<30 \mathrm{mg} / 24$ horas ou $<20 \mu \mathrm{g} /$ minuto

$<4$

Hematúrias glomerulares

Presentes

Presente* $>30 \mathrm{mg} / 24$ horas ou $>20 \mu \mathrm{g} /$ minuto

$\geq 4$

$$
\begin{array}{cc}
<0,5 \mathrm{~g} / 24 \text { horas ou } & \geq 0,5-1 \mathrm{~g} / 24 \text { horas ou } \\
<4 \mathrm{mg} / \mathrm{m}^{2} / \text { hora } & >4 \mathrm{mg} / \mathrm{m}^{2} / \text { hora }
\end{array}
$$
$\geq 1$
$<1$

Negativo

*Ainda não há consenso na literatura sobre um valor percentual limítrofe de dismorfismo eritrocitário para caracterização de hematúria glomerular. 
matinal com jejum, a relação proteína/creatinina está < 0,2 (normal), entre 0,2 e 0,5 (proteinúria leve), entre 0,5 e 2 (proteinúria moderada) e $>2$ (proteinúria maciça ou nefrótica). A presença de proteinúria inferior a $0,5 \mathrm{~g} / 24 \mathrm{~h}$ sugere sangramento não-glomerular, e em quantidade superior a $0,5-1 \mathrm{~g} / 24 \mathrm{~h}$, lesão glomerular ${ }^{(44,60,62)}$. Favaro et al. ${ }^{(19)}$ (1997) e Ward et al. ${ }^{(66)}$ (1998) ressaltaram maior eficácia da proteinúria como marcador para diagnóstico de hemorragia glomerular em crianças em relação aos critérios do dismorfismo eritrocitário. Entretanto, conforme estudos de Fasset et al. ${ }^{(17)}$ (1982), existem casos de glomerulonefrite nos quais ocorre sangramento com ausência de proteinúria, tornando-se a avaliação do dismorfismo crucial para a determinação da hematúria.

\section{Microalbuminúria}

Cerca de um terço das proteínas que escapam pela urina é albumina ${ }^{(4,5)}$, e, por ser quantidade inferior à sensibilidade das fitas reagentes de urina, não são detectadas em exame de rotina. Muitos estudos preconizam que valores para microalbuminúria de $20 \mu \mathrm{g} /$ minuto ou de $>30 \mathrm{mg} / 24$ horas seriam marcadores de lesão glomerular ${ }^{(4,19,44)}$. Favaro et al. ${ }^{(20)}$ (1994) relataram melhores resultados para detecção de lesão glomerular por meio desse método, quando em comparação com o método do dismorfismo eritrocitário.

\section{Volume médio das hemácias}

Este modelo baseia-se na diferenciação das curvas de distribuição de volume das hemácias por um auto-analisador de eritrócitos, semelhante aos adotados para hematimetria sangüínea ${ }^{(3,8,22,43,55)}$. Fundamenta-se no fato de que as hemácias, além de sofrerem modificações na forma, também diminuem seu volume ao atravessarem a membrana capilar dos glomérulos. Segundo Shichiri et al. ${ }^{(55)}$ (1988), se os eritrócitos urinários apresentarem volume médio inferior aos da corrente sangüínea, há forte suspeita de origem glomerular, e, caso apresentem volume maior, provavelmente a hematúria é de origem não-glomerular. Mais tarde, Oner et al.(43) (1991) descreveram que, se o valor da razão entre o volume médio das hemácias urinárias $\left(V_{C M}\right)$ e o volume corpuscular médio dos eritrócitos da circulação sangüínea $\left(V_{C M}\right)$ fosse $<1$, a hematúria estaria associada a glomerulopatias, e se a razão fosse $>1$, o sangramento seria de causa urológica. Caestecker et al. ${ }^{(8)}$ (1989) relataram maior eficácia dos auto-analisadores de eritrócitos em relação à microscopia de contraste de fase, bem como quantificaram o volume médio dos eritrócitos de origem glomerular (35-50fl) e dos não-glomerulares (65-148fl). Embora esse método seja defendido por alguns autores ${ }^{(3,22)}$, principalmente por não depender da qualidade do pesquisador e por ser reproduzido em qualquer laboratório, os aparelhos sofreriam constantes danos pelos sedimentos urinários e apresentariam erros mensurais na presença de restos celulares na urina ou quando a quantidade de hemácias fosse baixa.

\section{Teste de hemácias envolvidas com glicoproteína Tamm-Horsfall}

A glicoproteína Tamm-Horsfall foi descrita inicialmente por Hoyer e Seiler(26) (1979). Essa proteína é o principal constituinte dos cilindros urinários, sendo produzida pelas células tubulares e encontrada no lado luminal do segmento espesso da alça de Henle e do túbulo contorcido distal $(26,28)$. O princípio do teste se baseia na capacidade dessa proteína em envolver a superfície das hemácias de origem glomerular quando elas atingem os segmentos de Henle. Janssens et al.(28) (1992), por meio de imunofluorescência indireta e utilizando anticorpo policlonal, observaram que as hemácias cobertas por essa proteína eram, na maioria dos casos, de origem renal pura. No entanto, nos casos de hematúrias pós-renais, a positividade do teste foi encontrada na minoria dos casos. Esses achados foram criticados por alguns pesquisadores por resultarem de um método pouco acessível e demorado, bem como pelo uso de anticorpos policlonais ${ }^{(48,66)}$. Porém, há autores otimistas, que aguardam resultados de novos testes, principalmente com uso de anticorpos monoclonais ${ }^{(3,22)}$.

\section{Diagnóstico diferencial}

Embora esteja demonstrado na literatura que a presença de hemácias dismórficas apresenta boas sensibilidade e especificidade para hemorragias glomerulares, existem outras situações em que o dismorfismo também poderá ser encontrado, sem necessariamente existir lesão glomerular, como: infecção do trato urinário, cálculo renal, hipertrofia prostática, nefropatia de refluxo, estenose ureteropélvica, exercícios físicos, entre outros ${ }^{(11)}$. Do mesmo modo, vários autores também já relataram alterações glomerulares com ausência de dismorfismo eritrocitário, como em glomerulonefrites pós-estreptocócica, crescêntica e membranoproliferativa, síndrome hemolítico-urêmica e nefropatia membranosa ${ }^{(4,64)}$. 


\section{Tabela 5}

\section{Principais questionamentos apontados na literatura sobre a validação do dismorfismo} eritrocitário como marcador de hematúria glomerular

Diversidade de critérios para definição de dismorfismo eritrocitário

Variação do percentual de dismorfismo com a progressão da doença

Inadequação dos termos isomórfica e dismórfica

Variação do percentual de dismorfismo com o pH e a osmolaridade urinária

Indução de dismorfismo por distúrbios metabólicos

Mimetização do dismorfismo por inúmeras alterações eritrocitárias

Necessidade de observador experiente

Microscopia de contraste de fase como técnica dispendiosa

Difícil diferenciação entre acantócitos e células G1

Questionamento das formas específicas para lesão glomerular

\section{Investigação complementar}

$\mathrm{Na}$ investigação da etiologia de um sangramento urinário, é importante estabelecer se a hematúria se origina do glomérulo ou não, posto que os exames confirmatórios possam ser diferentes nestas situações. Portanto, muitos autores consideram que o estudo do dismorfismo eritrocitário representa um importante guia para propedêutica

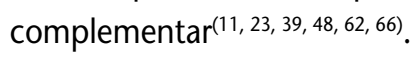

Na presença de hemácias dismórficas, a definição de certeza de sangramento glomerular deve ser somada à utilização de outros métodos de diagnóstico, como dosagens plasmáticas de uréia, creatinina, proteínas totais e frações, hemograma, complemento (C3 e C4), antiestreptolisina O (ASTO), fator antinuclear (FAN), sorologias para hepatites B e C, glicosúria, relação entre proteína/creatinina urinária e ultra-sonografia de vias urinárias, para afastar demais etiologias da hematúria ${ }^{(11,39,62)}$.

Por outro lado, no encontro de hemácias isomórficas, os exames complementares devem inicialmente voltar-se para a detecção de etiologias não-glomerulares, sendo eles: urocultura, calciúria, uricosúria, eletroforese de hemoglobina, ultra-sonografia de trato urinário, bexiga e próstata, uretrocistografia miccional, cistoscopia, urografia excretora, cintilografia renal e arteriografia renal $(11,23,48,66)$.

A biópsia renal, embora invasiva, pode ser necessária para a confirmação de diagnóstico, sendo considerada método confirmatório para inúmeras enfermidades nefrológicas ${ }^{(11,62,66)}$.

\section{Discussão}

Os parâmetros adotados por Birch e Fairley( ${ }^{(6)}$ (1979), bem como os estudos de Kohler et al. ${ }^{(19)}$ (1991) e Tomita et al. ${ }^{(20)}$ (1992), foram avaliados e repetidos por diversos autores, com concordância na maioria dos casos. Porém, inúmeras foram as observações apontadas na literatura sobre esses achados iniciais, visando a otimização e validação da pesquisa do dismorfismo eritrocitário. A Tabela 5 relata uma lista de dez considerações importantes que merecem ser discutidas.

1. Ausência de critérios para caracterização de dismorfismo: ainda não há critérios estabelecidos para um valor limítrofe do percentual de dismorfismo indicativo de lesão glomerular ${ }^{(21)}$. A porcentagem $>20 \%$ de células dismórficas é recomendada por boa parte dos estudos, porém, na literatura, esse valor pode variar de $10 \%$ a $80 \%$, com sensibilidade variando de $21 \%$ a $95 \%$ e especificidade entre $75 \%$ e $100 \%$ para adultos. Em estudos pediátricos, os valores adotados também se mostraram variados, entre $20 \%$ e $80 \%$, com sensibilidade de $52 \%$ a $100 \%$ e especificidade entre $81 \%$ e $100 \%$ (Tabela 3).

2. Variação de percentual do dismorfismo com a progressão da doença: Van Isegham et al.(64) (1983), avaliando glomerulonefrite pós-estreptocócica, e Gu Xian-Shi (citado por Van Isegham et al. $\left.{ }^{(64)}\right)$, relatando um caso de febre hemorrágica, questionaram a validade do dismorfismo como marcador precoce de hematúria glomerular ao demonstrarem predomínio de hemácias isomórficas na fase aguda dessas doenças, com identificação de células dismórficas em seus estádios mais avançados. 
3. Inadequação do termo isomórfica $x$ dismórfica: a utilização dessa classificação para as hemácias urinárias não procede. Segundo Roth et al. ${ }^{(53)}$ (1991), é natural que as hemácias não-glomerulares sofram alterações em sua forma, independente de se em menor intensidade, ao deixarem o leito vascular e alcançarem a urina, com diferenças no $\mathrm{pH}$ e na osmolaridade, embora haja concordância quanto ao maior grau de deformação em hemácias de origem glomerular. O mais prudente seria a omissão do termo isomórfica e a nomeação apenas de hemácias não-glomerulares.

4. Variação com o pH e a osmolaridade urinária: o dismorfismo eritrocitário é mais bem caracterizado em urinas mais ácidas e concentradas $(29,34,36,51,52)$. Alguns estudos relataram queda do percentual de dismorfismo em urinas que não apresentaram as características acima. Schuetz et al.(54) (1985), comparando a sedimentoscopia urinária em pacientes com glomerulonefrite antes e após indução de diurese, observaram uma redução importante de $62 \%$ para $20 \%$ do dismorfismo eritrocitário.

5. Indução de dismorfismo eritrocitário por distúrbios metabólicos: Stapleton et al. ${ }^{(59)}$ (1994) alertaram para a indução de dismorfismo eritrocitário pela presença de hipercalciúria e/ou hiperuricosúria, sem necessariamente haver foco de lesão glomerular.

6. Inúmeras alterações eritrocitárias podem mimetizar um dismorfismo: Rath et al. ${ }^{(50)}$ (1992) relataram alterações em hemácias de origem não-glomerular expostas à acidez urinária, com retração de membrana e hipocromia, semeIhantes a hemácias fantasmas, porém não se caracterizando como dismorfismo eritrocitário.

7. Necessidade de observador experiente: alguns estudos verificaram resultados discrepantes entre seus observadores, utilizando trabalhos pareados ${ }^{(9,12)}$. O grande número de hemácias isomórficas dificultaria a identificação das formas dismórficas, presentes em menor quantidade, sendo a presença de cilindros hemáticos de grande importância para auxílio do diagnóstico.

8. A microscopia de contraste de fase como técnica dispendiosa: o alto custo do material, a obrigação do diagnóstico imediato e a incapacidade de arquivo de lâminas são o grande dispêndio deste método. Devido aos motivos enumerados, essa técnica foi criticada por alguns pesquisadores $(6,10,14,18,50,58)$. Visando a promover acesso universal da técnica descrita por Birch e Fairley ${ }^{(7)}$ (1979), muitos trabalhos, como o de Chang ${ }^{(10)}(1984)$ e Roth et al.(53) (1991), validaram o estudo do dismorfismo com a microscopia ótica convencional ao adotarem colorações (corante de Wright e Papanicolaou, respectivamente) para destacar os elementos figurados da sedimentoscopia urinária. O uso de soluções fixadoras alcoólicas e a coloração pelo método de Papanicolaou, rotineiro para estudo da citologia oncológica urinária, também foram seguidos por

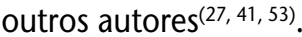

9. Difícil diferenciação entre acantócitos e células G1: a distinção entre essas duas formas celulares foi questionada por alguns autores, na literatura, que acreditam se tratar do mesmo tipo celular ${ }^{(25,42)}$. Embora Tomita et al. ${ }^{(61)}(1992)$ relatassem melhores resultados analisando as células G1, o encontro de acantócitos proposto por Kholer et al. ${ }^{(35)}$ (1991) poderia resultar em dados semelhantes, caso tivessem estudado urinas concentradas e mais ácidas.

10. Questionamento das formas específicas para lesão glomerular: embora a maioria das pesquisas sobre dismorfismo eritrocitário validasse esses achados ${ }^{(1,4,35,61)}$, há estudos que ainda questionam esses dados ${ }^{(19,20)}$. Zaman e Proesmans ${ }^{(67)}$ (2000) concluíram que a associação entre a presença de $>1 \%$ células G1 e > 50\% de dismorfismo não apresentou resultados confiáveis para um diagnóstico de certeza para lesão de foco glomerular.

\section{Conclusões}

O estudo do dismorfismo eritrocitário pela análise do sedimento urinário para avaliação do foco de sangramento urinário, se glomerular ou não, embora apresente alguns resultados conflitantes na literatura, é bem recomendado pela maioria dos autores. Apesar de ainda não existir um consenso na literatura sobre qual porcentagem de dismorfismo eritrocitário deve ser adotada para definir hematúria glomerular, alguns estudos consideram a presença de pelo menos $20 \%$ de hemácias dismórficas, e outros aconselham a adoção do percentual $>80 \%$ de dismorfismo para um diagnóstico preciso de lesão glomerular. Por outro lado, ao considerar a identificação de acantócitos ou de células G1, a maioria dos trabalhos propõe adoção de um percentual $>5 \%$. Quanto ao método adotado para a pesquisa do dismorfismo, a técnica convencional pela microscopia de contraste de fase mostrou ser igualmente substituível pelas microscopias ótica e eletrônica e por analisadores de imagem computadorizados, com eficácias equivalentes, apesar de ligeira preferência pela forma clássica. Apesar dos demais marcadores urinários para definição da origem da hematúria, diversas discussões na literatura apontam prós e contras para todos os atualmente existentes, mostrando a carência de um marcador ideal, com método simples, rápido, eficiente e de aceitação universal. Por fim, a adoção do 
dismorfismo eritrocitário continua sendo bem recomendada pela maioria dos autores, principalmente por ser um impor- tante guia de investigação para propedêutica complementar durante a investigação da origem das hematúrias.

\section{Referências}

I.ABDURRAHMAN, M. B. et al. Diagnostic value of phase contrast microscopy in haematuria. Trop Geogr Méd, v. 37, p. 171-4, 1985.

2. AHMAD, G.; SEGASOTHY, M.; MORAD, Z. Urinary erythrocyte morphology as a diagnostic aid in haematuria. Singapore Med J, v. 43, p. 486-8, 1993.

3. ANGULO,J. C. et al.The value of comparative volumetric analysis of urinary and blood erythrocytes to localize the source of hematuria.J Urol, v. 162, p. I 19-26, 1999.

4. BASTOS, M. G.; MARTINS, G. A.; PAULA, R. B. Diagnóstico diferencial na hematúria. J Bras Nefrol, v. 20, p. 425-40, 1998.

5. BECKER, G. J.; FAIRLEY, K. F. Urinalysis. In: MASSRY, S. G.; GLASSOCK, R. J. Textbook of Nephrology. 3. ed. London: Williams \& Williams, 1995. p. 1751-67.

6. BIRCH, D. F. et al. Urinary erythrocyte morphology in the diagnosis of glomerular hematuria. Clin Nephrology, v. 20, p. 78-84, 1983.

7. BIRCH,D. F.;FAIRLEY,K. F. Hematúria: glomerular or nonglomerular? Lancet, v. 2, p. 845-6, 1979.

8. CAESTECKER, M. P. et al. Localization of haematuria by red cell analysers and phase contrast microscopy. Nephron, v. 52, p. 170-3, 1989.

9. CATALA, J. L. L.; FABREGAS, M. B. Acanthocyturia is more efficient in to differentiate glomerular from non-glomerular hematuria then dysmorphic erythrocytes. Arch Esp Urol, v. 55, p. 164-6, 2002.

10. CHANG, B. S. Red cell morphology as a diagnostic aid in hematúria. JAMA, v. 252, p. 1747-9, 1984.

I I. COHEN, R. A.; BROWN, R. S. Microscopic hematuria. N Engl J Med, v. 348, p. 2330-8, 2003.

I2. CROMPTON, C. H.;WARD, P.B.; HEWITT, I. K.The use of urinary red cell morphology to determine the source of hematuria in children. Clin Nephrol, v. 39, p. 44-9, 1993.

13. DE SANTO, N. G. et al. Phase contrast microscopy of the urine sediment for the diagnosis of glomerular and nonglomerular bleeding-data in children and adults with normal creatinine clearance. Nephron, v. 45, p. 35-9, 1987.

14. DI PAOLO, N. et al. A new method of evaluating urinary erythrocyte dysmorphisms in glomerulonephritis. Clin Nephrol, v. 39, p. 50-2, 1993.

15. DINDA, A. K. et al. Diagnosis of glomerular haematuria: role of dysmorphic red cell, GI cell and bright-field microscopy. Scand J Clin Lab Invest, v. 57, p. 203-8, 1997.

16. FASSET, R. G. et al. Scanning electron microscopy of glomerular and nonglomerular red blood cells. Clin Nephrol, v. 20, p. | |-6, 1983.

17. FASSET, R. G. et al. Detection of glomerular bleeding by phasecontrast microscopy. Lancet, v. I, p. 1432-4, 1982.
18. FASSET, R. G. et al. Urinary red cell morphology during exercise. BrMed J, v. 285, p. I455-7, 1982.

19. FAVARO, S. et al. Is the red cell morphology really useful to detect the source of hematuria? Am J Nephrol, v. 17, p. 172-5, 1997.

20.FAVARO, S. et al. Microhematuria associated with microproteinuria. Clin Nephrol, v. 4I, p. 56, 1994.

21. GAI, M. et al. About urinary erythrocyte dysmorphism. Nephrol Dial Transplant, v. 17, p. I533, 2002.

22. GAME, X. et al. Comparison of red blood cell volume distribution curves and phase-contrast microscopy in localization of the origin of hematuria. Urology, v. 6I, p. 507- I I, 2003.

23. GIRNDT, M.; KOHLER, H. Differential diagnosis of urinary findings. MMW Fortschr Med, v. I46, p. 29-33, 2004.

24. GROSSFELD, G. D. et al. Asymptomatic microscopic hematuria in adults: summary of the AUA best practice policy recommendations. Am Fam Physician, v. 63, p. I |45-54, 200 I.

25. HEINE, G. H. et al. Acanthocytes in the urine: useful tool to differentiate diabetic nephropathy from glomerulonephritis? Diabetes Care, v. 27, p. 190-4, 2004.

26. HOYER, J. R.; SEILER, M.W. Pathophysiology of Tamm-Horsfall protein. Kidney Int, v. 16, p. 279-89, 1979.

27. HUUSSEN, J. et al. The (fixed) urinary sediment, a simple and useful diagnostic tool in patients with haematuria. Neth J Med, v. 62, p. 4-9, 2004.

28. JANSSENS, P. M. et al. Distinction between renal and nonrenal hematuria using immunoperoxidase staining of erythrocytes in urine forTamm-Horsfall protein. NedTijdschr Geneeskd, v. 136, p. 1605-10, 1992.

29. JONES, B. F. Urine osmolality and urinary red cell morphology. Nephron, v. 59, p. 157, 1991.

30. KESSON, A. M. et al. Microscopic examination of urine. Lancet, v. 14, p. 809-12, 1978.

31. KINCAID-SMITH, P.et al. Acute renal failure and tubular necrosis associated with hematuria due to glomerulonephritis. Clin Nephrol, v. 19, p. 106-II, 1983.

32. KINCAID-SMITH, P. Haematuria and exercise-related haematuria. Br Med J, v. 285, p. I595-6, 1982.

33. KITAMOTO,Y. et al. Differentiation of hematuria using a uniquely shaped red cells. Nephron, v. 64, p. 32-6, 1993.

34. KITAMOTO, Y. et al. The mechanism of glomerular dysmorphic red cell formation in the kidney. Tohoku J Exp Med, v. 167, p. 93-105, 1992.

35. KOHLER, H. et al. Acanthocyturia: a characteristic marker for glomerular bleeding. Kidney International, v. 40, p. I 15-20, 1991.

36. KUBOTA, H. et al. Mechanism of urinary erythrocyte deformity in patients with glomerular disease. Nephron, v. 48, p. 338-9, 1988. 
37. LETTGEN, B.; WOHLMUTH, A. Validity of GI-cells in the differentiation between glomerular and non-glomerular haematuria in children. Pediatr Nephrol, v. 9, p. 435-7, 1995.

38. LING, S. H. et al. A new morphological classification of urinary erythrocytes for evaluating the source of hematúria. Zhonghua Nei Ke Za Zhi, v. 33, p. 255-8, 1994.

39. LOH, E. H. et al. Blood cells and red cell morphology in the urine of healthy children. Clin Nephrol, v. 34, p. 185-7, 1990.

40. MESSING, E. M. et al. Hematuria home screening: repeat testing results.J Urol, v. | 54, p. 57-61, 1995.

4I. MOHAMMAD, K. S. et al. Phase contrast microscopic examination of urinary erythrocytes to localise source of bleeding: an overlooked technique? J Clin Pathol, v. 46, p. 642-5, 1993.

42. NGUYEN, G. K. Urine cytology in renal glomerular disease and value of $\mathrm{GI}$ cell in the diagnosis of glomerular bleeding. Diagn Cytopathol, v. 29, p. 67-73, 2003.

43. ONER, A. et al. Identification of the source of haematuria by automated measurement of mean corpuscular volume of urinary red cells. Pediatr Nephrol, v. 5, p. 54-5, 1991.

44. PENIDO, M. G. M. G. Estudo da excreção urinária de cálcio, ácido úrico e citrato em pré-escolares, escolares e adolescentes utilizando-se amostras colhidas em 24 horas, em tempo determinado e em micção matinal única com e sem jejum 1995. Tese (doutoramento) - Faculdade de Medicina, Universidade Federal de Minas Gerais, Belo Horizonte.

45. PERRONE, H. C. et al. Associação de hematúria e hipercalciúria na infância. Rev Ass Med Br, v. 34, p. 129-32, 1988.

46. PERRONE, $H$. C. et al. Metabolic disturbance as a cause of recurrent hematuria in children. Kidney Int, v. 39, v. 707-I0, 1991.

47. PILLSWORTH,T. J. et al. Differentiation of renal from non-renal hematuria by microscopic examination of erythrocytes in urine. Clin Chem, v. 33, p. 1791-5, 1987.

48. PRIOR, J.; GUIGNARD, J. P. Hematuria in the child. Investigation plan in pediatric practice. Arch Pediatr, v. 5, p. 799-807, 1998.

49. RAMAN, G.V. et al. A blind controlled trial of phase-contrast by two observers for evaluation the source of haematuria. Nephron, v. 44, p.304-8, 1986.

50. RATH, B. et al. Evaluation of light microscopy to localize the site of hematúria. Arch Dis Child, v. 65, p. 338-40, 1990.

5।. RATH, B. et al. What makes red cells dysmorphic in glomerular hematúria? Ped Nephrol, v. 6, p. 424-7, 1992.
52. RIZZONI, G. et al. Evaluation of glomerular and nonglomerular hematúria by phase-contrast microscopy.J Pediatr, v. I03, p. 370-4, 1983.

53. ROTH, S. et al. Microscopic hematuria: advances in identification of glomerular dysmorphic erythrocytes. J Urol, v. I 46, p. 680-4, I991.

54. SCHUETZ, E. et al. Effect of diuresis on urinary erythrocyte morphology in glomerulonephritis. Klin Wschr, v. 63, p. 575-7, 1985.

55. SHICHIRI, M. et al. Ped-cell-volume distribution curves in diagnosis of glomerular and non-glomerular haematuria. Lancet, v. I, p. 908- I I, 1988.

56. SIGALA, J. F. et al. Red blood cell casts in acute interstitial nephritis. Arch Intern Med, v. 138, p. 1419-21, 1978.

57. STAPLETON, F. B. et al. Dysmorphic erythrocytes in children with hematúria. Pediatr Res, v. 17, p. 1628-31, 1983.

58. STAPLETON, F. B. Morphology of urinary red blood cells: a simple guide in localizing the site of hematuria. Pediatr Clin North Am, v. 34, p. 56I-9, 1987.

59. STAPLETON, F. B. Hematuria associated with hypercalciuria and hyperuricosuria: a practical approach. Pediatr Nephrol, v. 8, p. 756-6I, 1994

60.THAL, S. M. et al. Comparison of dysmorphic erythrocytes with other urinary sediment parameters of renal bleeding. Am J Clin Pathol, v. 86, p. 784-7, 1986.

61.TOMITA, M. et al. A new morphological classification of urinary erythrocytes for differential diagnosis of glomerular hematuria. Clin Nephron, v. 37, p. 84-9, 1992.

62.TROMPETER, R. S.; BARRATT,T. M. Clinical evaluation: hematuria. In: HOLLIDAY, M.A. et al. Pediatric nephrology. 3. ed. Baltimore: Williams \& Wilkins, 1994. p. 366.

63.VAN DER SNOEK, B. E. et al. Dysmorphic erythrocytes in urinary sediment in differentiating urological from nephrological causes of hematuria. Ned Tijdschr Geneeskd, v. 138, p. 721-6, 1994.

64. VAN ISEGHAM, P. et al. Urinary erythrocyte morphology in acute glomerulonephritis. Br Med J, p. 287-8, 1983.

65.VEHASKARI,V. M. et al. Microscopic hematuria in school children: epidemiology and clinic-pathologic evaluation.J Pediatr, v. 95, p. 676-84, 1979.

66. WARD, J. F. et al. Refined microscopic urinalysis for red blood cell morphology in the evaluation of asymptomatic microscopic hematuria in a pediatric population.J Urol, v. I 60, p. I 492-5, 1998.

67. ZAMAN, Z:; PROESMANS, W. Dysmorphic erythrocytes and GI cells as markers of glomerular hematuria. Pediatr Nephrol, v. |4, p. 980-4, 2000 . 